\title{
Adoptive lymphocyte transfer to an HIV-infected progressor from an elite controller
}

\author{
Stephen A. Migueles, ${ }^{1}$ Cheryl Chairez, ${ }^{1}$ Siying Lin, ${ }^{1}$ Noah V. Gavil, ${ }^{1}$ Danielle M. Rosenthal, ${ }^{1}$ \\ Milad Pooran, ${ }^{2}$ Ven Natarajan, ${ }^{3}$ Adam Rupert, ${ }^{3}$ Robin Dewar, ${ }^{3}$ Tauseef Rehman, ${ }^{3}$ Brad T. Sherman, ${ }^{3}$ \\ Joseph Adelsberger, ${ }^{3}$ Susan F. Leitman, ${ }^{4}$ David Stroncek, ${ }^{4}$ Caryn C. Morse, ${ }^{2}$ Mark Connors, ${ }^{1}$ \\ H. Clifford Lane, ${ }^{1}$ and Joseph A. Kovacs ${ }^{2}$ \\ 'Laboratory of Immunoregulation, National Institute of Allergy and Infectious Diseases, NIH, Bethesda, Maryland, USA. \\ ${ }^{2}$ Critical Care Medicine Department, NIH Clinical Center, NIH, Bethesda, Maryland, USA. ${ }^{3}$ Leidos Biomedical Research Inc., \\ Frederick National Laboratory for Cancer Research, Frederick, Maryland, USA. ${ }^{4}$ Department of Transfusion Medicine, NIH \\ Clinical Center, NIH, Bethesda, Maryland, USA.
}

BACKGROUND. HIV-infected patients with poor virologic control and multidrug-resistant virus have limited therapeutic options. The current study was undertaken to evaluate the safety, immunologic effects, and antiviral activity of peripheral lymphocytes transferred from an elite controller, whose immune system is able to control viral replication without antiretroviral medications, to an HLA-B*2705-matched progressor.

METHODS. Approximately 22 billion cells were collected from an elite controller by lymphapheresis and infused within 6 hours into a recipient with a preinfusion $\mathrm{CD4}^{+} \mathrm{T}$ cell count of 10 cells $/ \mu \mathrm{L}(1 \%)$ and HIV plasma viral load of 114,993 copies/mL.

RESULTS. Donor cells were cleared from the recipient's peripheral blood by day 8. A transient decrease in viral load to 58,421 (day 3 ) was followed by a rebound to 702,972 (day 6) before returning to baseline values by day 8 . The decreased viral load was temporally associated with peak levels of donor T cells, including CD8 ${ }^{+} \mathrm{T}$ cells that had high levels of expression of Ki67, perforin, and granzyme B. Notably, recipient CD8 ${ }^{+} \mathrm{T}$ cells also showed increased expression of these markers, especially in HIV-specific tetramer-positive cells.

CONCLUSION. These results suggest that the adoptive transfer of lymphocytes from an HIVinfected elite controller to an HIV-infected patient with progressive disease may be able to perturb the immune system of the recipient in both positive and negative ways.

TRIAL REGISTRATION. ClinicalTrials.gov NCT00559416.

FUNDING. Intramural Research Programs of the US NIH Clinical Center and the National Institute of Allergy and Infectious Diseases (NIAID); the National Cancer Institute.

Conflict of interest: SAM, HCL, and JAK are investigators on a clinical trial of pembrolizumab being conducted under a Cooperative Research and Development Agreement between the NIH and Merck Sharp \& Dohme Corp.

Copyright: (c) 2019, American Society for Clinical Investigation.

Submitted: May 28, 2019

Accepted: August 12, 2019

Published: September 19, 2019.

Reference information: JCI Insight.

2019;4(18):e130664.

https://doi.org/10.1172/jci.

insight.130664.

\section{Introduction}

The development of highly effective combination antiretroviral therapies (cARTs) has resulted in dramatic improvement in AIDS-free survival among HIV-infected persons (1-3). However, lifelong treatment is required and may be associated with acute and chronic drug toxicities and, in a subset of patients, the emergence of resistant strains of HIV (4-6). Resistance has been documented with all drug classes, and for a small number of patients, there are currently no available cART regimens to suppress multidrug-resistant virus levels in plasma below detection limits of current assays. Because poorly controlled viral replication leads to progression of HIV-associated immunodeficiency, alternative therapeutic approaches for such patients need to be investigated.

Cell-mediated immunity is one of the most important mechanisms to control viral infections such as HIV. Both $\mathrm{CD}^{+}$and $\mathrm{CD} 8^{+} \mathrm{T}$ cells play critical roles. HIV infection impairs the function of both $\mathrm{CD} 4^{+}$and $\mathrm{CD} 8^{+} \mathrm{T}$ cells, compromising the ability of the host to combat infections and resulting in ongoing viremia, progressive 
immune dysfunction, and ultimately development of opportunistic diseases (7-9). However, a small proportion of HIV-infected individuals known as elite controllers (ECs) are able to suppress HIV replication without therapy $(9,10)$. In these patients, there is sustained restriction of viral replication, presumably in part because of a more effective immune response directed toward the virus. Certain human leukocyte antigen (HLA) genotypes, including $\mathrm{B}^{*} 27$ and $\mathrm{B}^{*} 57$, are overrepresented in the EC population. This suggests an important role for $\mathrm{CD}^{+}$cytotoxic $\mathrm{T}$ lymphocytes (CTLs) in the control of HIV replication in ECs $(11,12)$. The demonstration of enhanced HIV-specific $\mathrm{CD}^{+} \mathrm{T}$ cell responses in ECs compared with chronic progressors has lent further support to the hypothesis that CTLs play a dominant role in mediating control $(13,14)$. These enhanced responses include killing of autologous HIV-infected $\mathrm{CD} 4^{+} \mathrm{T}$ cells by $\mathrm{CD} 8^{+} \mathrm{T}$ cells, which is one of the strongest correlates of elite control identified to date and is closely associated with expression levels of the effector molecules perforin and granzyme B $(7,15,16)$. In contrast, HIV-specific CD8 ${ }^{+} \mathrm{T}$ cells of chronic progressors proliferate poorly and have very low cytotoxic capacity.

Thus one potential therapeutic approach is to transfer virus-specific T cells from ECs with natural, immune-mediated control of HIV infection to patients with uncontrolled infection. Studies of transferred virus-specific allogeneic $\mathrm{T}$ cells, primarily $\mathrm{CD}^{+} \mathrm{T}$ cells, to patients with reactivation of $\mathrm{CMV}$, EBV, and other viruses following stem cell transplantation have shown that such transferred cells can safely induce a significant reduction in viral loads $(17,18)$. Few similar studies using virus-specific cells have been undertaken in HIV-infected patients. Transfer of syngeneic PBMCs from an HIV-uninfected twin to an HIV-infected twin has been associated with transient increases in $\mathrm{CD}^{+} \mathrm{T}$ cell counts and adoptive transfer of cellular immunity to the neoantigen keyhole limpet hemocyanin (19). Transfer of HIV-specific CTL clones or chimeric antigen receptor $\mathrm{T}$ cells with specificity for HIV has been uniformly unsuccessful in decreasing viral loads or increasing CD4 counts (20-24). In a simian immunodeficiency virus (SIV) rhesus macaque model, transfer of allogeneic $\mathrm{CD}^{+} \mathrm{T}$ cell clones specific for SIV gag or tat that were derived from a chronically infected animal (matched to $1 \mathrm{MHC}$ allele in the recipient animals) had no effect on viral load (25). Lack of benefit may have resulted from use of cells from donors that did not spontaneously control viral replication.

The current study was undertaken as a proof of concept to examine the safety, immunologic effects, duration of cell survival, and potential antiviral activity of peripheral lymphocytes adoptively transferred from an EC to a progressor matched on the protective allele HLA-B*2705. This is one of several HLA molecules associated with high-level control of HIV-1. CD8 ${ }^{+} \mathrm{T}$ cells specific for HIV peptides restricted by this HLA are thought to mediate potent cytotoxic capacity associated with immunologic control.

\section{Results}

The recipient was a 57-year-old White male with HIV infection diagnosed 28 years previously. He had a history of cryptococcal meningitis, pneumocystis pneumonia, and candidal esophagitis. He had been on multiple cART regimens since 1992. On his current regimen of etravirine, darunavir/ritonavir, and emtricitabine at study enrollment, his $\mathrm{CD}^{+} \mathrm{T}$ cell count was 10 cells $/ \mu \mathrm{L}(1 \%)$, and his HIV plasma viral load was 156,934 copies/mL. He remained on the same cART regimen throughout the study. The following HIV resistance-associated mutations were identified by genotyping: reverse transcriptase: K65R, K70R, V75I, F77L, K103N, V108I, Y115F, F116Y, V118I, E138Q, Q151M, Y181C, M184V, H208Y, and P225H; protease: L10F, V11I, V32I, L33F, M36I, M46I, I47V, F53L, I54L, A71I, G73A, V82S, L89V, and L90M; and integrase: L74M, T97A, and Y143C. This indicated intermediate- to high-level resistance to all available antiretroviral drugs (ARVs) other than dolutegravir, to which there was potential low-level resistance.

The donor was a 49-year-old White male with HIV infection diagnosed in 2000. His CD4 count had always been measured above 500 cells $/ \mu \mathrm{L}$, and his plasma viral load was consistently fewer than 40 copies/ $\mathrm{mL}$. He had never received ARVs and had no history of any HIV-related opportunistic diseases. Genotyping of $\mathrm{CD}^{+} \mathrm{T}$ cell-associated HIV RNA identified no resistance mutations. Donor and recipient were matched only at HLA-B*2705 and HLA-Cw*02 (Table 1).

Analysis of pretransfer PBMCs showed that, although the magnitude and breadth of the HIV-specific $\mathrm{CD}^{+} \mathrm{T}$ cell response in the donor exceeded those in the recipient (Figure 1, A and B), the response was predominantly focused on the B27-restricted Gag KK10 epitope in both patients (Figure 1C). Of the total B27/HIV Gag KK10 tetramer-positive $\mathrm{CD}^{+} \mathrm{T}$ cells in both patients, a greater fraction in the donor was capable of increased expression of the antiviral cytokine IFN- $\gamma$ and the degranulation marker CD107a (Figure 1D and refs. 14, 16, 26). In addition, $\mathrm{CD}^{+} \mathrm{T}$ cell recognition of targets pulsed with a KK10 variant peptide containing the R264Q and L268M sequence mutations that were present within the recipient's 
Table 1. HLA type of donor and recipient

\begin{tabular}{ccc}
\hline HLA Class & Donor & Recipient \\
A & 24,31 & 02,68 \\
B & 27,27 & 07,27 \\
C & 02 & 02,07 \\
\hline DRB & $3^{*} 02,4^{*} 01$ & $5^{*} 01: 01$ \\
\hline DQB1 & 03,03 & $05: 04,06$ \\
DRB1 & 04,11 & 01,15 \\
\hline
\end{tabular}

autologous virus (based on the 9-kb sequences) was maintained in both the recipient and donor (Figure 1E). Finally, despite evidence of alloreactivity based on increased background $\mathrm{CD} 8^{+} \mathrm{T}$ cell responses to heterologous uninfected $\mathrm{CD} 4^{+} \mathrm{T}$ cell targets (7), donor $\mathrm{CD}^{+} \mathrm{T}$ cells exhibited high levels of degranulation and cytotoxic activity in response to autologous and heterologous $\mathrm{CD} 4^{+} \mathrm{T}$ cells superinfected with the recipient's virus (Figure $1, \mathrm{~F}$ and $\mathrm{G}$ ). In contrast, low net responses were observed in recipient $\mathrm{CD} 8^{+} \mathrm{T}$ cells to autologous and heterologous superinfected $\mathrm{CD} 4^{+} \mathrm{T}$ cells, along with the high background that was indicative of alloreactivity (Figure 1G). Overall, these results suggested that highly functional HIV-specific $\mathrm{CD}^{+} \mathrm{T}$ cells from the donor should be able to recognize and to mount a robust immune response to the recipient's autologous virus upon adoptive transfer.

On day 0 , in July 2014, the donor underwent a 20-L lymphapheresis; $2 \times 10^{8}$ lymphocytes $/ \mathrm{kg}(\sim 22 \times$ $10^{9}$ total cells, $67 \%$ lymphocytes) were harvested and infused into the recipient 5 hours after completion of the apheresis. The recipient developed an episode of fever during the first day (maximum temperature of $38.5^{\circ} \mathrm{C}$ ), with chills and body aches during the next few days that resolved with acetaminophen, and transient nausea that resolved with ondansetron. All symptoms resolved by day 6 after the cell infusion. Transient hypomagnesemia, hypocalcemia, hypophosphatemia, and thrombocytopenia were also seen and resolved by day 10 . No clinical or laboratory toxicities greater than grade 2 (DAIDS toxicity table, version 1.0) were seen. The recipient was followed for approximately 4 months after the infusion, during which time he was clinically stable with no new medical problems.

Two hours after the infusion, approximately $3 \%$ of the cells in peripheral blood were from the donor; by 12 hours this had dropped to approximately 1\%. Donor cells disappeared rapidly (Figure 2A) so that by day 9 after infusion, the levels had dropped below the level of detection $(<1: 50,000-100,000)$. HLA antibody testing, which was negative at baseline, showed low levels of antibodies to donor HLA molecules HLA-A:24 and HLA-DQ:7,8,9 at day 22.

At days 2 and 3 after the infusion, there was a decrease in viral load from a baseline of 114,993 copies/mL to 68,960 and 58,421 copies/mL, respectively (Figure 2, B and C). This was followed by a rapid increase to 702,972 copies $/ \mathrm{mL}$ at day 6 , with a return to 174,073 copies $/ \mathrm{mL}$ by day 8 . Based on next-generation sequencing, the virus responsible for the after-infusion increase in plasma viral load was recipient and not donor virus.

The CD4 count showed a small increase during this period but remained below 20 cells/ $\mu \mathrm{L}$ throughout (Figure 3). In contrast, following an initial decrease in total $\mathrm{CD}^{+}$cell numbers after the infusion, there was a substantial increase to greater than 1000 cells/ $\mu \mathrm{L}$ beginning on day 6 . This coincided with the increased viral load. Subsequently, the $\mathrm{CD}^{+}$cell number gradually decreased to baseline $(\sim 450-600 \mathrm{cells} / \mu \mathrm{L})$ by week 2 (Figure 3). Approximately $70 \%$ of these $\mathrm{CD}^{+}$cells were activated memory cells as defined by coexpression of CD38, HLA-DR, and CD45RO.

To examine potential mediators of the clinical symptoms associated with the cell infusion, we examined plasma cytokine/chemokine levels. Increases temporally associated with symptoms were seen most prominently in IFN- $\gamma$, CXCL10 (IP-10), IL-2, and IL-10 (Figure 4); increases were also seen in CCL2, CCL4, TNF- $\alpha$, GM-CSF, IL-5, IL-6, IL-15, and IL-12/IL-23p40. All cytokines returned to approximate baseline levels by day 5 after infusion.

Using more detailed flow cytometric determination of $\mathrm{T}$ cell markers of phenotype and function, we found that the recipient's $\sim 2$-fold reduction from baseline in plasma HIV RNA levels on days 2 to 3 was temporally associated with peak detection of HLA-A2 $2^{-}$donor T cells on days 1 (CD3 ${ }^{+} \mathrm{CD} 8^{-}, 9.07 \%$; 
A

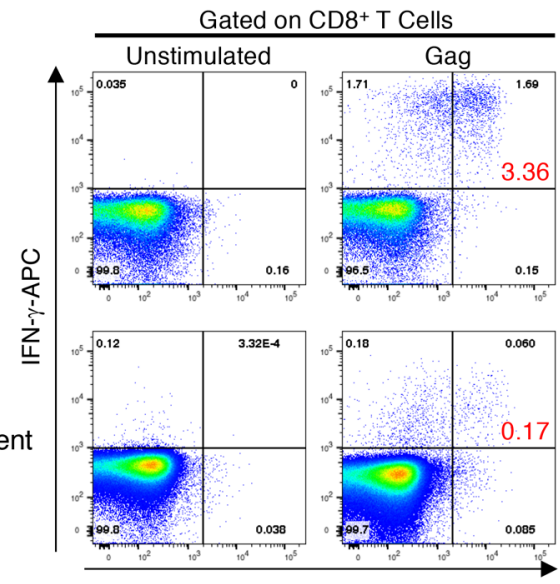

CD107a-PE Cy7
B

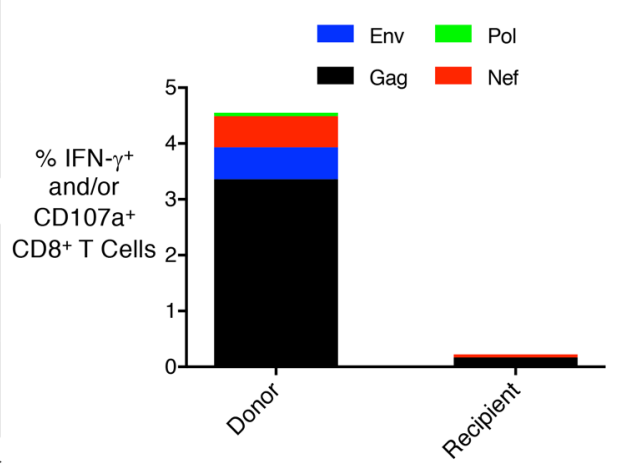

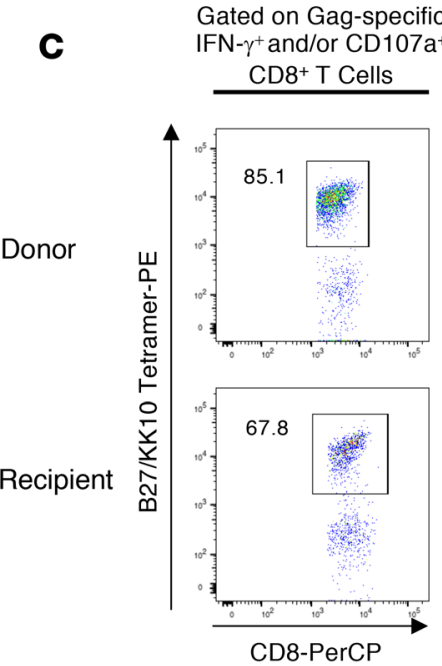

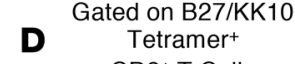

E
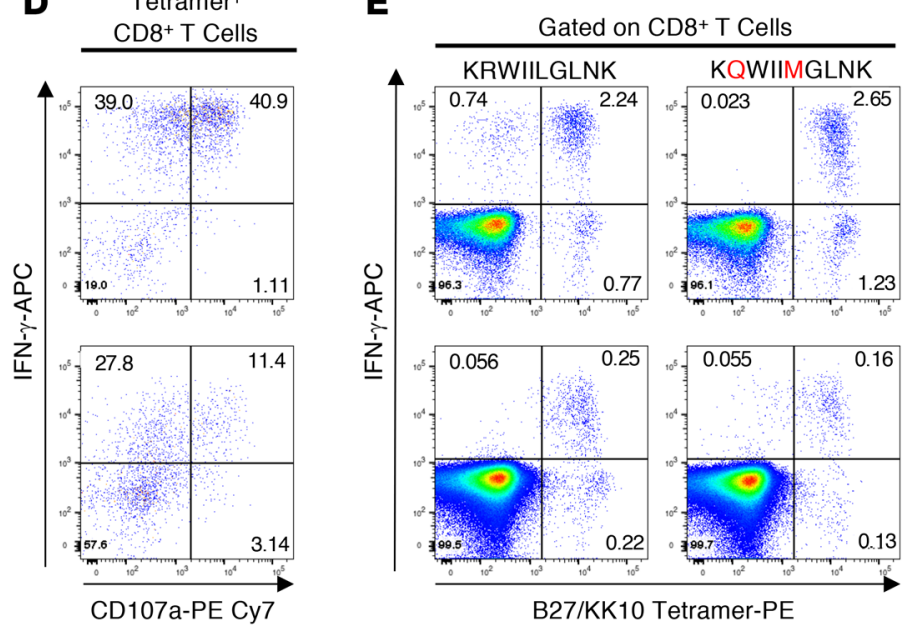

$\mathbf{F}$
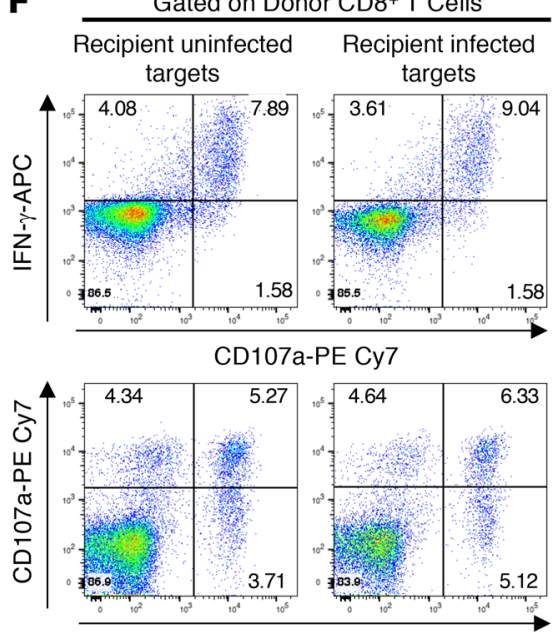

G

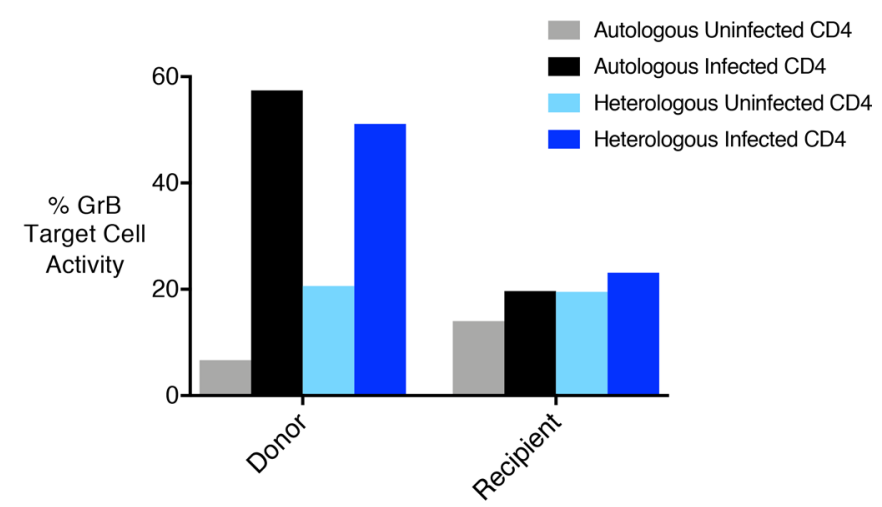

Figure 1. Donor and recipient pretransfer PBMCs shared the immunodominant B27-restricted HIV Gag KK10-specific CD8+ ${ }^{+}$cell response that was highly functional in the donor and maintained recognition of recipient viral variant sequences. (A) Representative flow plots gated on donor (top row) and recipient (bottom row) $\mathrm{CD}^{+} \mathrm{T}$ cells after 6-hour incubation with medium alone (unstimulated, left column) or a pool of Gag 15-mer peptides (right column) in the presence of Golgi inhibitors and the anti-CD107a PE-Cy7-labeled monoclonal antibody before surface and intracellular staining and flow cytometric analysis (see Methods). Red numbers indicate net frequencies of IFN- $\gamma^{+}$and/or CD107a+CD8 ${ }^{+} T$ cells after background subtraction. (B) Summary of donor and recipient IFN- $\gamma^{+}$and/or CD107a+CD8 ${ }^{+}$T cell responses determined as in A to overlapping peptide pools spanning HIV-1 Env (shown in blue), Nef (shown in red), Gag (shown in black), and Pol (shown in green) gene products. Background responses to medium have been subtracted. (C) The majority of donor (top plot) and recipient (bottom plot) CD8 ${ }^{+}$ 
T cells responding to Gag by producing IFN- $\gamma$ and/or expressing CD107a stain positively with the B27/HIV Gag KK10 tetramer. (D) A greater fraction of donor (top plot) versus recipient (bottom plot) B27/HIV Gag KK10 tetramer-positive CD8 ${ }^{+}$T cells are functional based on the capacity to produce IFN- $\gamma$ and/or express CD107a. (E) Donor (top row) and recipient (bottom row) IFN- $\gamma^{+}$CD8 ${ }^{+} \mathrm{T}$ cells are shown in response to autologous PBMCs pulsed with consensus sequence KK10 (left column) or a peptide containing the $\mathrm{R} 264 \mathrm{Q}$ and $\mathrm{L} 268 \mathrm{M}$ sequence variations harbored within the recipient's autologous virus (right column). (F) The percentages of total donor IFN- $\gamma^{+}$and/or CD107a+CD8 ${ }^{+}$T cells in response to recipient uninfected (left column) or HIV-infected (right column) targets (top row). Percentages of donor tetramer-positive and tetramer-negative $\mathrm{CD}^{+} \mathrm{T}$ cells expressing CD107a after stimulation with the same targets are shown in the bottom row. Black numbers on plots represent percentages of gated cells. (C) Summary of donor or recipient CD8 ${ }^{+} \mathrm{T}$ cell cytotoxic responses to autologous or heterologous uninfected or HIV-infected CD4 ${ }^{+} T$ cell targets is shown. Cytotoxicity was measured by flow cytometry based on granzyme B activity in targets following a 1-hour incubation with CD8 ${ }^{+}$ T cell effectors. The HIV isolate used to infect all targets was recovered from recipient CD4+ $\mathrm{T}$ cells.

$\left.\mathrm{CD}^{+} 8^{+}, 1.19 \%\right)$ and $3\left(\mathrm{CD}^{+} \mathrm{CD}^{-}, 12.1 \%\right.$; $\mathrm{CD}^{+} \mathrm{CD}^{+}, 0.86 \%$; Figure $5, \mathrm{~A}$ and $\left.\mathrm{B}\right)$. These kinetics were similar to those measured in the chimerism assay and also consistent with the changes over time in the low frequencies of $\mathrm{CD}^{-}$lymphocytes, likely representing B cells $\left(\mathrm{CD}^{-} \mathrm{CD} 8^{-}, \leq 0.41 \%\right)$ and $\mathrm{NK}$ cells $\left(\mathrm{CD}^{-}\right.$ $\mathrm{CD}^{+}, \leq 0.78 \%$; Figure $5 \mathrm{~B}$ ). A majority of baseline donor total and HIV tetramer-positive $\mathrm{CD}^{+} \mathrm{T}$ cells exhibited a CCR7-CD27 ${ }^{+}$effector memory phenotype that shifted to mostly CCR7-CD27- effector cells after transfer (Figure 6A and refs. 27, 28). In addition, increased expression of Ki67 (8.11\%) and high-level expression of perforin $(60.5 \%)$ and granzyme B (74.9\%) were noted in donor total $\mathrm{CD}^{+} \mathrm{T}$ cells by day 3 compared with very low baseline levels $(0.88 \%, 7.44 \%$, and $27.1 \%$, respectively; Figure 6, B-E). Donor tetramer-positive $\mathrm{CD} 8^{+} \mathrm{T}$ cells were discernible in low numbers only on days 1 and 3 (Figure 5C). Not unexpectedly, recipient $\mathrm{CD}^{+} \mathrm{T}$ cells were also primarily CCR7- at baseline, as observed in donor cells; however, differences in the percentages that expressed CD27 were noted between recipient total and HIV tetramer-positive $\mathrm{CD} 8^{+} \mathrm{T}$ cells. As seen in the donor cells, both recipient total and HIV tetramer-positive $\mathrm{CD}^{+} \mathrm{T}$ cells became more "effector like," with reduced CD27 expression on days 1 and 3 following adoptive transfer, before returning to baseline levels (Figure 6A). Somewhat unexpectedly, recipient $\mathrm{CD} 8^{+} \mathrm{T}$ cells also exhibited markedly increased Ki67 (6.62\%), perforin (64.9\%), and granzyme B (84\%) following cell infusion that declined to baseline levels $(1.65 \%, 28.8 \%$, and $60.9 \%$, respectively) by day 13 . These early increases were even greater in recipient-derived tetramer-positive CD8 ${ }^{+} \mathrm{T}$ cells $(42.6 \%, 78.6 \%$, and 94.5\%, respectively; Figure 6, B-E). As supported by the cytokine data, this increased activation, cycling, and upregulation of cytotoxic proteins in recipient HIV Gag KK10-specific CD8 ${ }^{+} \mathrm{T}$ cells likely occurred in response to the heightened immune activation induced by the transfer of heterologous PBMCs.

The phenotype of donor and recipient $\mathrm{CD}^{+} \mathrm{CD} 8^{-}$lymphocytes, which are primarily $\mathrm{CD} 4^{+} \mathrm{T}$ cells, was also examined (although this population might have included low frequencies [1-3\% of total $\mathrm{T}$ cells] of immunoregulatory double-negative [CD4-CD8-] T cells, consisting of $\gamma / \delta$, double-negative, and NK T cell subsets [ref. 29]). The phenotype of donor $\mathrm{CD} 4^{+} \mathrm{T}$ cells remained predominantly $\mathrm{CCR} 7^{+} \mathrm{CD} 27^{+}(\mathrm{cen}-$ tral memory) following infusion, although $\mathrm{CCR} 7^{-} \mathrm{CD} 27^{-}$(effector) cells transiently increased at day 1 . In contrast, baseline recipient $\mathrm{CD} 4^{+} \mathrm{T}$ cells, which were primarily $\mathrm{CCR} 7^{-} \mathrm{CD} 27^{+}$(effector memory), shifted to predominantly $\mathrm{CCR} 7^{+} \mathrm{CD} 27^{+}$by day 3 , coincident with increased cycling of these cells as determined by Ki67 expression, before eventually reverting to their original phenotype by day 13 (Figure 7).

\section{Discussion}

The current study, the first to our knowledge in which lymphocytes were transferred from an $\mathrm{HIV}^{+} \mathrm{EC}$ to an $\mathrm{HIV}^{+}$progressor, demonstrates that such a cell transfer is clinically safe and can lead to a transient decrease in plasma levels of $\mathrm{HIV}$, a transient but modest increase in $\mathrm{CD}^{+}$cell numbers, and a subsequent burst in plasma viremia. It is likely that none of these changes is of clinical significance. We transferred cells from an $\mathrm{HIV}^{+} \mathrm{EC}$ because the donor's immune system had already demonstrated the ability to restrict HIV replication. The donor and recipient were matched at the HLA-B27 allele, which had been demonstrated to be the element responsible for restricting the immunodominant HIV-specific $\mathrm{CD} 8^{+} \mathrm{T}$ cell response in this individual (Figure 1).

Transferred cells were lost very rapidly because of an alloresponse. This possibility was anticipated given the lack of any type of therapy to prevent rejection, although long-term microchimerism has been demonstrated in immunocompetent patients receiving blood transfusions (30). Of note, substantial, transient immunologic perturbations were noted in both donor and recipient $\mathrm{CD} 4^{+}$and $\mathrm{CD} 8^{+} \mathrm{T}$ cells.

The decrease in viral load was temporally associated with detectable donor cells, including HIV tetramer-positive $\mathrm{CD}^{+} \mathrm{T}$ cells that demonstrated increased expression of perforin and granzyme $\mathrm{B}$, suggesting that they played a role in restricting viral replication. These findings support the important role of $\mathrm{CD} 8^{+} \mathrm{T}$ cells in controlling HIV infection that has been clearly demonstrated in animal studies (31-33). 

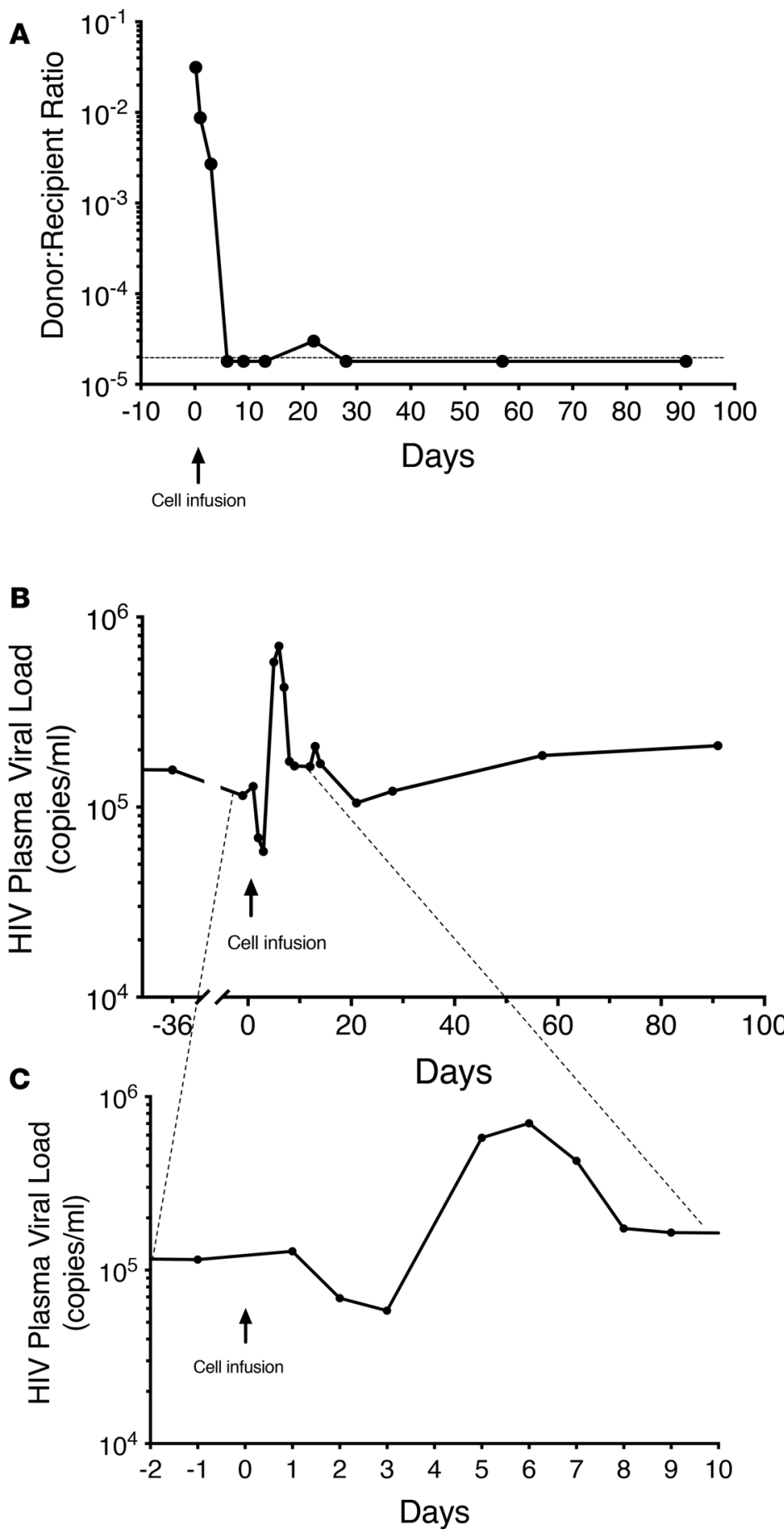

Figure 2. Levels of donor cells and plasma HIV over time following infusion of $\sim 15$ billion donor lymphocytes ( 22 billion total cells). (A) Ratio of donor to recipient cells, as determined by quantitative PCR, over time. There was a rapid loss of donor cells so that by day 6 donor cells were at or below the level of detection. The $y$ axis shows the ratio of donor to recipient cells and uses a log scale. (B and C) Changes in HIV plasma viral levels over time. The $y$ axis in both panels shows plasma HIV levels using a log scale. $\mathbf{C}$ is an expansion of the timeline shown in $\mathbf{B}$ to demonstrate the changes seen in the immediate after-infusion period. There was a transient decline in viral load immediately following the infusion that was temporally associated with detectable transferred cells, following which there was a viral rebound before a return to baseline levels. The time of cell infusion is indicated by the arrow. 

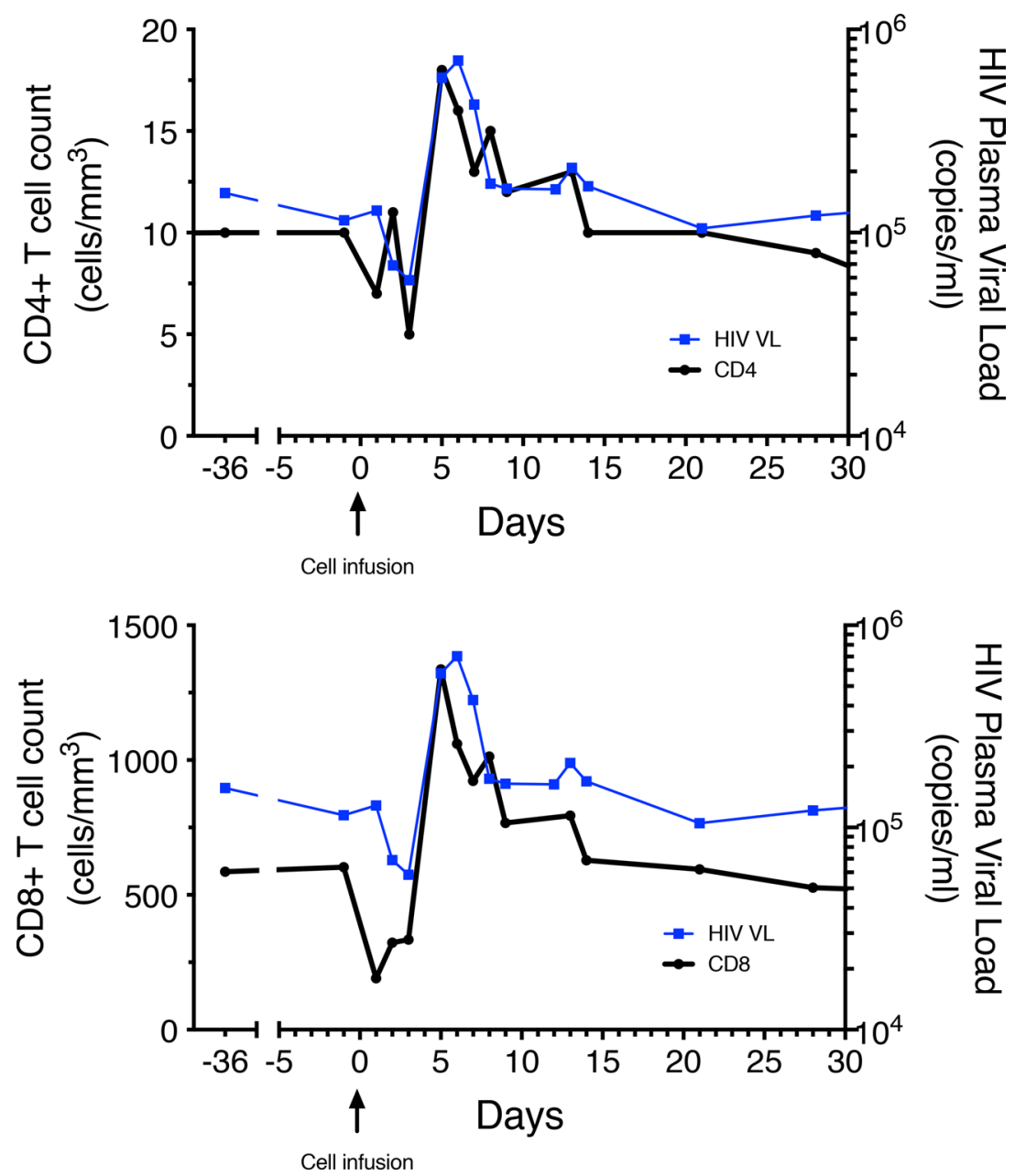

Figure 3. Changes in $\mathrm{CD4}^{+}$and $\mathrm{CD8}{ }^{+} \mathrm{T}$ cell numbers over time following the cell infusion. There was a transient decrease in both $\mathrm{CD} 4^{+}$and $\mathrm{CD} 8^{+} \mathrm{T}$ cell numbers immediately after the infusion, followed by an increase in both populations, though the absolute increase in $\mathrm{CD}^{+} \mathrm{T}$ cell numbers was modest ( 10 cells/ $\left.\mu \mathrm{L}\right)$. CD4 ${ }^{+}$and $\mathrm{CD} 8^{+}$cell numbers are shown by the black circles and lines. HIV plasma viral load during the same period is indicated by the blue squares and lines. The time of cell infusion is indicated by the arrow.

We used PBMCs rather than purified $\mathrm{CD} 8^{+} \mathrm{T}$ cells because of the possible role of $\mathrm{CD} 4^{+} \mathrm{T}$ cells in controlling viral replication in ECs through direct antiviral activity or enhancing CD8 function (34-37). Donor $\mathrm{CD} 4^{+} \mathrm{T}$ cells were detectable during the period of viral suppression, and exhibited a central memory phenotype, although an effector phenotype was seen at day 1 . The temporal association between increased Ki67 and reduced CCR7 expression suggested this phenotypic shift might be explained by relative expansion of $\mathrm{CCR} 7^{-} \mathrm{CD} 4^{+} \mathrm{T}$ cells; however, the predominant mechanism is difficult to determine because multiple processes might be operative, including trafficking into tissue, activation-induced CCR7 downregulation, contraction/death of CCR $7^{+}$cells, or expansion of CCR7- cells (28). Although these changes could represent a response to HIV, a major component of the activation of both $\mathrm{CD} 4^{+}$and $\mathrm{CD} 8^{+}$donor $\mathrm{T}$ cells is likely an early graft-versus-host response. Similarly, the activation of recipient cells probably reflects in large part the alloreactive response that resulted in the rapid clearance of donor cells. This robust alloreactive response as well as the de novo antibody response to the donor HLAs is noteworthy given the profound immunosuppression in the recipient. Intriguingly, this alloreactivity may also have contributed to the transient decrease in plasma HIV levels by activating anti-HIV-specific cells of the recipient (38).

The recipient exhibited mild flulike symptoms for a few days after infusion. This was associated with increases in select cytokines, especially IFN- $\gamma$ and related pathways. It was interesting that IFN- $\gamma$, IL-2, CCL4 (MIP-1ß), and TNF- $\alpha$ were among the cytokines and chemokines whose levels increased 

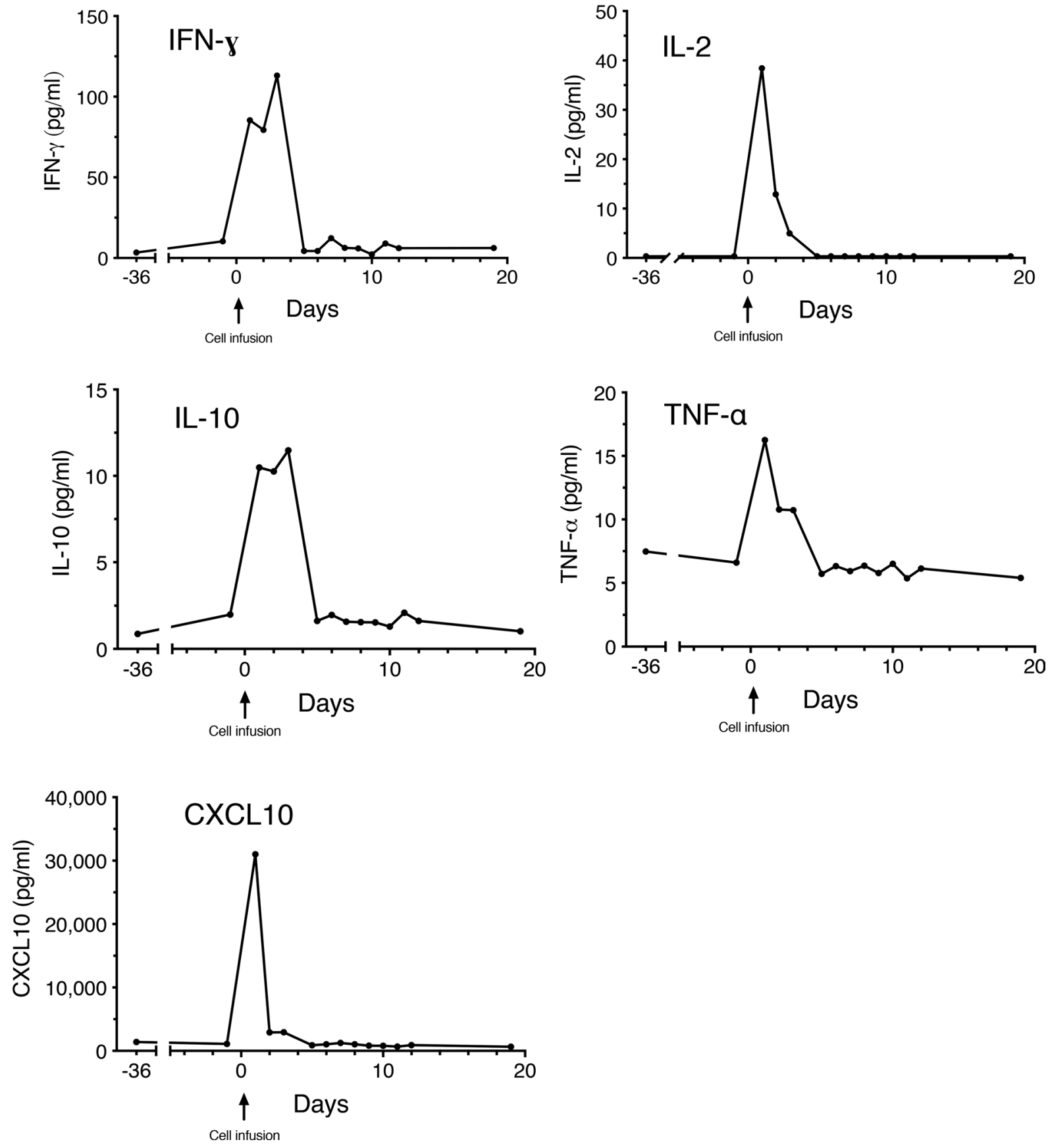

Figure 4. Changes in plasma levels of select cytokines over time following the cell infusion. Transient increases in IFN- $\gamma$, IL-2, IL-10, TNF- $\alpha$, and $C X C L 10$ were seen immediately following the infusion, before a return to baseline levels. The time of cell infusion is indicated by the arrow.

transiently after transfer at the time of reduction in plasma viral load and expansion of donor and recipient cytotoxic protein-expressing $\mathrm{CD} 8^{+} \mathrm{T}$ cells. HIV-specific $\mathrm{CD} 8^{+} \mathrm{T}$ cells able to simultaneously express these antiviral factors have been observed at higher frequencies in the blood and mucosal tissues of ECs compared with progressors and to diminish over time in patients with poorly controlled HIV replication $(14,26,39)$. IL-15 levels also increased transiently in the recipient, which might have had mixed effects on the capacity of T cells to mediate control over HIV (40-43).

Using cells from an HIV-infected donor could result in superinfection of the recipient with a different HIV strain. However, based on sequencing of cell-associated HIV RNA, the donor virus had no drug resistance mutations, consistent with his history of never receiving ARVs, and the recipient was on a regimen predicted to be active against the donor virus. Although there was an increase in HIV plasma 

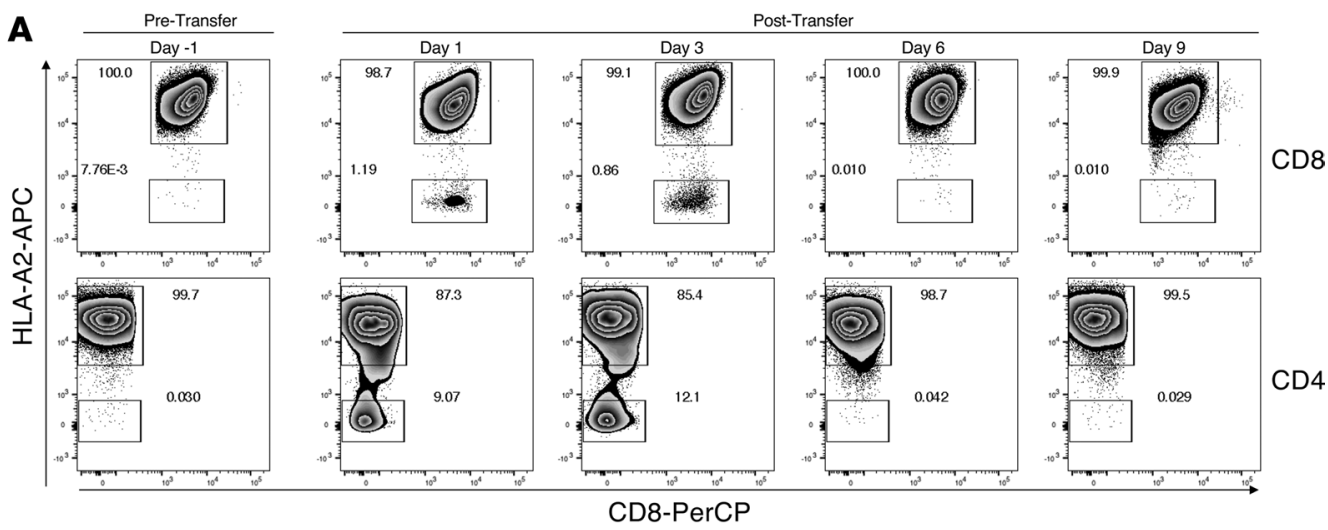

B

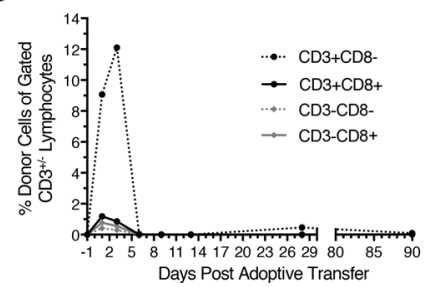

C

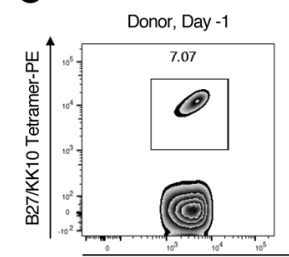

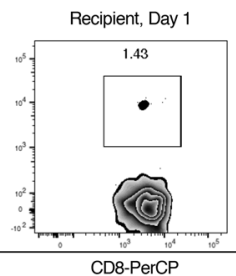

Recipient, Day 3

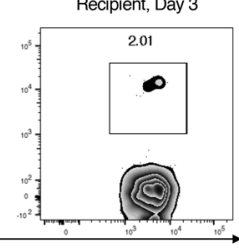

Figure 5. Donor and recipient cells could be distinguished in recipient blood by flow cytometric detection with anti-HLA-A2 monoclonal antibody staining. (A) Representative flow plots depict how donor (HLA-A2-) and recipient $\left(\mathrm{HLA}-\mathrm{A2} 2^{+}\right) \mathrm{T}$ cells were enumerated by flow cytometry. $\mathrm{CD}^{+}$lymphocytes were gated on $\mathrm{CD} 8^{+}$(top row) or CD8 $8^{-}$cells (approximately representative of CD4+ cells; bottom row) in recipient samples taken before day -1 (left column) or after days 1-9 (right columns) adoptive transfer. (B) Summary of donor-derived CD3+CD8+ (solid black line), CD3 ${ }^{+} C D 8^{-}$(dotted black line), CD3-CD8 (solid gray line), and CD3-CD8- (dotted gray line) lymphocytes after adoptive transfer through day 90 are shown. (C) Donor (HLA-A2-) immunodominant CD8 ${ }^{+}$T cells specific for the HLA-B27-restricted HIV-1 Gag epitope KK10 were detected until day 3 after transfer. The pretransfer cells from the donor are shown in the first panel, while the donor cells in the recipient from days 1 and 3 after transfer are shown in the next 2 panels. Gating was on $\mathrm{CD}^{+} \mathrm{HLA}-\mathrm{A2} 2^{-}$cells; only the $\mathrm{CD8} 8^{+}$cells are shown. The numbers within the flow plots in $\mathbf{A}$ and $\mathbf{C}$ indicate the percentage of cells within the boxed areas.

levels after the initial decline, sequencing demonstrated that the virus was exclusively recipient and not donor derived. This transient increase potentially resulted from the immune activation that occurred in conjunction with the alloreactive clearance of donor cells.

Although only a single patient received a cell transfer under this protocol, and thus the results must be interpreted with caution, this study nonetheless suggests that improving $\mathrm{CD} 8^{+} \mathrm{T}$ cell function may improve host control of HIV. This study was undertaken as a proof of concept; the approach used would be difficult to implement on a large scale because of the need to identify an HLA-compatible EC. Further, based on the rapid clearance of donor cells, additional interventions to prolong their survival (e.g., immunosuppressive drugs) would be needed, which would potentially increase the risks and reduce potential benefits. Although prior attempts to improve immune control of HIV have been unsuccessful, including cell transfers or bone marrow transplants from uninfected identical twins (19), transfers of clones targeting HIV-specific proteins (44), or broad activation of T cells with IL-2 alone or combined with an anti-CD3 antibody (45-47), these data suggest that immunotherapies targeting improvement of CD8 function, such as immune checkpoint inhibitors $(48,49)$, may contribute to control of viremia.

\section{Methods}

Study design. This open-label study was an exploratory trial to evaluate the safety of cell transfer as a potential salvage therapy in patients with limited therapeutic options and to determine the duration of survival of donor lymphocytes. Secondary goals included examining changes in plasma HIV levels and $\mathrm{CD} 4^{+} \mathrm{T}$ cell numbers. It was initially designed to enroll 3 recipients; however, the study was closed after enrollment of 1 recipient-donor pair because of difficulties in recruitment.

Enrollment criteria. Detailed eligibility criteria are provided in the Supplemental Data (supplemental material available online with this article; https://doi.org/10.1172/jci.insight.130664DS1). 

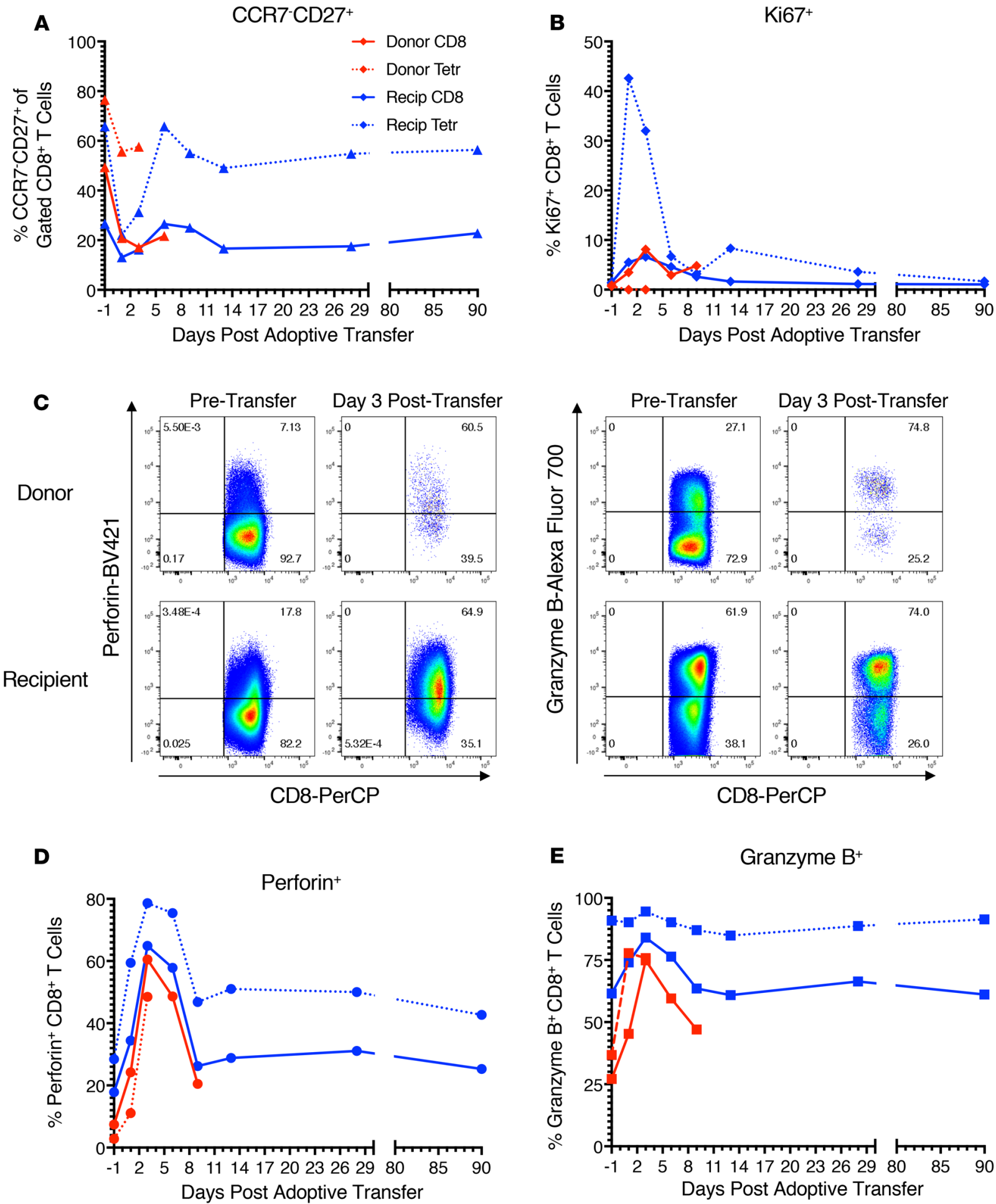

E Granzyme B+

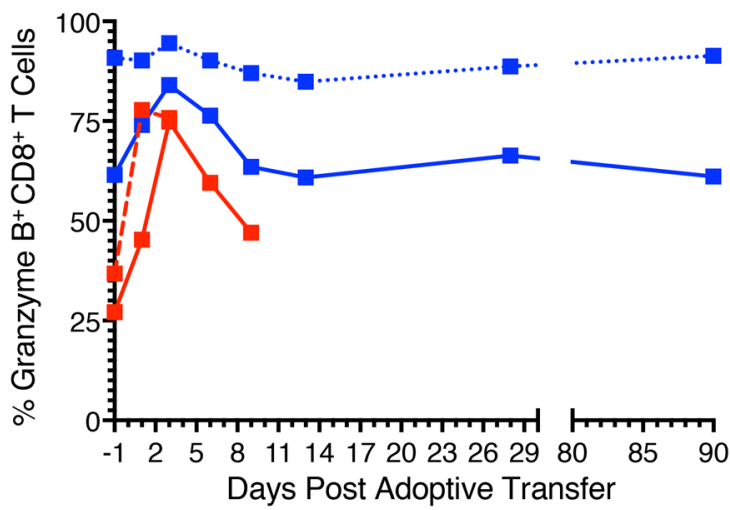

Figure 6. Donor and recipient total and HIV-specific $\mathrm{CDB}^{+} \mathrm{T}$ cells became more effector like and exhibited increased cycling and cytotoxic protein expression after transfer that were temporally associated with reductions in plasma HIV RNA levels. (A) Changes in the percentages of CCR7-CD27 ${ }^{+}$total (solid lines) or HLA-B27/Gag tetramer-positive (dotted lines) CD8 ${ }^{+} \mathrm{T}$ cells from the recipient (blue triangles) and donor (red triangles) are shown before and days after adoptive transfer. (B) Ki67 expression of total (solid lines) or HLA-B27/Gag tetramer+ (dotted lines) CD8 ${ }^{+}$T cells from the recipient (blue diamonds) and donor (red diamonds) are shown at the same time points around adoptive transfer. (C) Representative flow plots of perforin (left plots) and granzyme $B$ (right plots) expression of gated donor (top row) and recipient (bottom row) total CD8 ${ }^{+}$T cells before transfer and day 3 after transfer. (D and E) Summary data of perforin (D, circles) and granzyme B (E, squares) expression in total (solid lines) or HLA-B27/Gag tetramer-positive (dotted lines) CD8 ${ }^{+}$T cells from the donor (red symbols) and recipient (blue symbols) are shown over time. In all panels, pretransfer donor values were derived from cells obtained from the donor; all other values were derived from cells obtained from the recipient before or after transfer. 
A

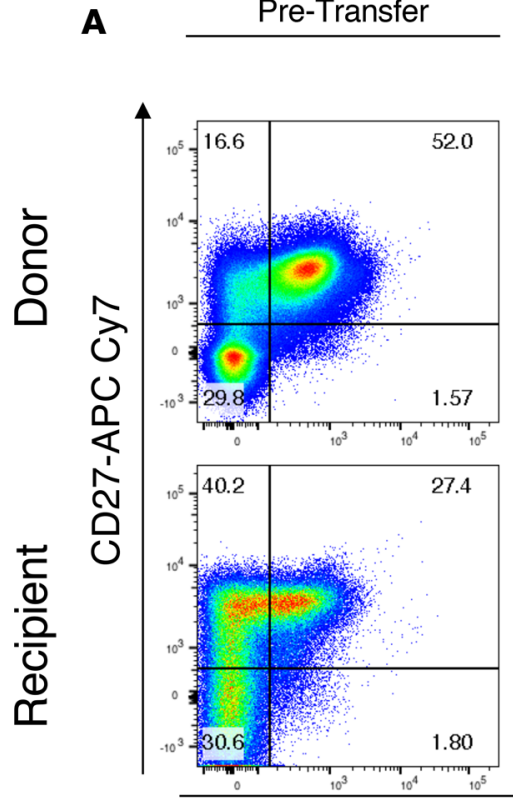

Post-Transfer

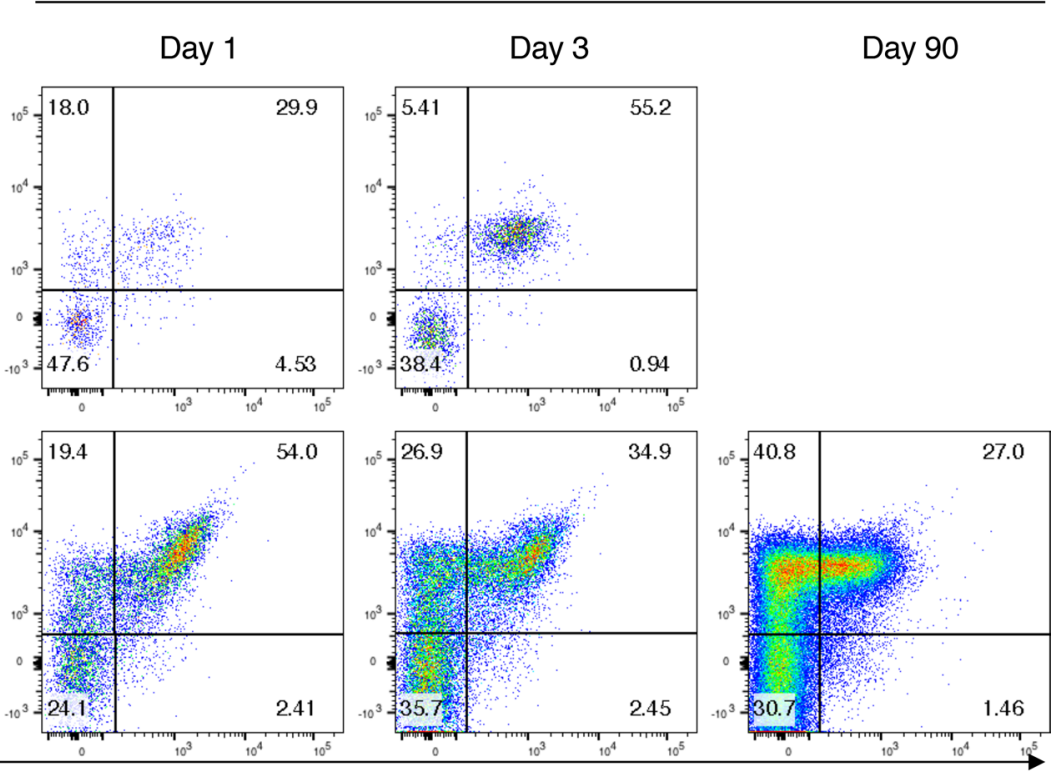

CCR7-PE Cy7

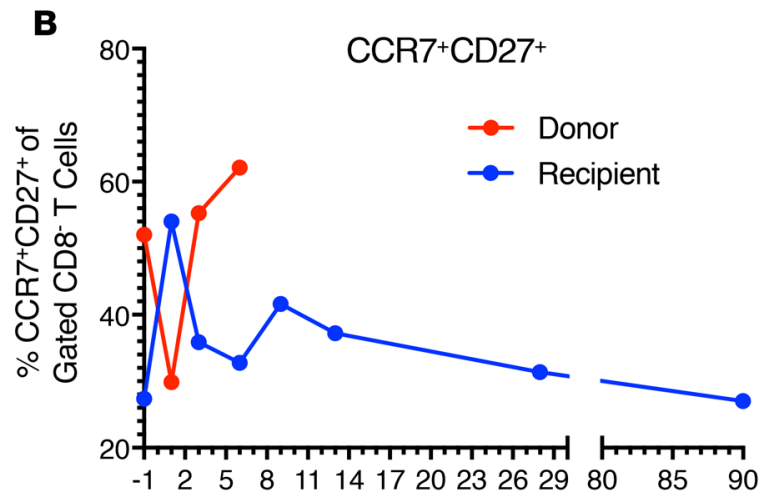

C

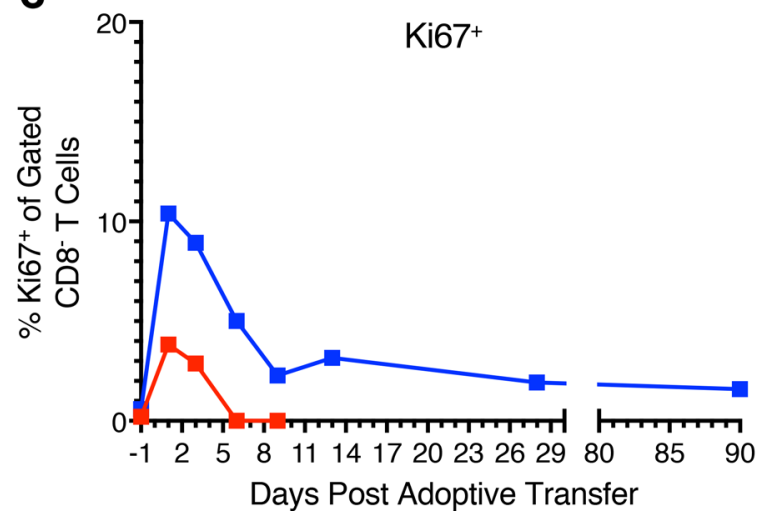

Figure 7. Phenotype of donor and recipient CD4 ${ }^{+} \mathbf{T}$ cells changed after transfer, then reverted back to baseline. (A) Gated on $C D 4^{+}\left(C D 8^{-}\right) \mathrm{T}_{\text {cells, }}$ donor (HLA-A2') cells (top row), which were primarily CCR $7^{+} \mathrm{CD} 27^{+}$before transfer (left column), were predominantly CCR7-CD27- on day 1 before reverting to a $C C R 7^{+} \mathrm{CD} 27^{+}$phenotype by day 3 (right columns). In contrast, recipient (HLA-A2+) cells (bottom row), which were primarily $\left[C R 7^{-} \mathrm{CD} 27^{+}\right.$ before transfer (left column), were predominantly CCR7 ${ }^{+}$CD27 $7^{+}$on day 1 before reversion to a CCR7-CD27+ phenotype (right columns). (B) Trends of recipient (blue symbols) and donor (red symbols) CCR7+CD27+CD4+ T cells over time. (C) Ki67 expression of gated recipient (blue symbols) and donor (red symbols) CD4+ (CD8-) T cells over time. In all panels, pretransfer donor results were derived from cells obtained from the donor; all other results were derived from cells obtained from the recipient before or after transfer.

Briefly, patients 18 years or older with confirmed HIV infection were eligible as recipients if they had an HIV plasma viral load more than 10,000 copies/mL on available optimized cART, failure or intolerance of at least 2 previous combination antiretroviral regimens, and a CD 4 count of fewer than 350 cells $/ \mu \mathrm{L}$. Donors were ECs matched to at least 1 HLA-B allele of the potential recipient at a 2-digit resolution or higher.

Study procedures. All visits were at the NIH Clinical Center. At enrollment, donor and recipient underwent a history and physical examination, safety laboratory evaluation, flow cytometry to enumerate CD4 ${ }^{+}$ and $\mathrm{CD}^{+} \mathrm{T}$ cell numbers and subsets, and genotyping of plasma virus (recipient) and cell-associated RNA (donor) to evaluate for HIV resistance mutations.

The recipient underwent, as a safety measure, GM-CSF-induced mobilization of hematopoietic stem cells, followed by apheresis to collect and store autologous stem cells, which would be available for future use in the event that transfusion-associated graft-versus-host disease developed $(50,51)$. After more than 2 weeks, the donor underwent lymphapheresis to collect approximately $2.0 \times 10^{8}$ lymphocytes $/ \mathrm{kg}$. 
These unmodified cells were then infused into the recipient 5 hours after collection. During the first 2 weeks following lymphocyte transfer, blood was drawn frequently for evaluation of safety and for analysis of chimerism, lymphocyte subsets, and plasma viral load, with subsequent visits weekly, then monthly. Anti-HLA antibodies were measured 3 weeks after the cell transfer.

HIV quantitation and sequence analysis. HIV plasma viral load was measured by the RealTime HIV-1 Assay (Abbott Laboratories; lower limit of quantification 40 copies/mL). Donor HIV was sequenced using the TruGene HIV-1 Genotyping Kit (Siemens Molecular Diagnostics), using RNA extracted from CD4 ${ }^{+} \mathrm{T}$ cells. The resulting donor sequence included the protease-coding (codons 4-99) and reverse transcription-coding (RT-coding) (codons 38-247) regions. For recipient HIV, RT-PCR followed by next-generation sequencing was performed on 3 and 12 samples to sequence a 9-kb nearly full-length region or the 2.6-kb polymerase gene, respectively. Multiple sequence alignment was performed using Clustal Omega (52). Detailed methods are provided in the supplemental Data.

Flow cytometry and functional assays. $\mathrm{CD}^{+}$and $\mathrm{CD} 8^{+} \mathrm{T}$ cell counts and subsets were enumerated using flow cytometry with BD Multitest CD3/CD8/CD45/CD4 kit (BD Biosciences). Blood was collected in a heparinized syringe or by leukapheresis, and then lymphocytes were separated by density centrifugation using Lymphocyte Separation Medium (MP Biomedicals). Cryopreserved PBMCs were thawed and rested overnight at $37^{\circ} \mathrm{C}$ and $4 \% \mathrm{CO}_{2}$ before specialized flow analyses. Recipient HIV was cultured by activating recipient $\mathrm{CD}^{+} \mathrm{T}$ cells, purified by glycerol gradient ultracentrifugation (maximum 106,750 g); SW 32 Ti rotor, Beckman Coulter), and titrated to determine the optimal dilution, yielding $50 \%$ infection of normal CD4 ${ }^{+} \mathrm{T}$ cells based on intracellular detection of p24 by flow cytometry using RD1-conjugated KC57 antibody (Beckman Coulter). Activated donor and recipient $\mathrm{CD} 4^{+} \mathrm{T}$ cells superinfected with this virus preparation were used in functional assays. Briefly, $\mathrm{CD}^{+} \mathrm{T}$ cells were positively selected from cryopreserved PBMCs by magnetic automated cell sorting (AutoMACS, Miltenyi Biotec) and polyclonally stimulated (15). A fraction of CD4 lymphoblasts were magneto-infected on day 3 with magnetized recipient virus (16). Percentage of infection was quantified as the frequencies of HIV-1 Gag p $24^{+} \mathrm{CD} 4^{+/-} \mathrm{CD} 3^{+}$targets by flow cytometry. In cytotoxicity assays, $\mathrm{CD} 8^{+} \mathrm{T}$ cell effectors that had been stimulated for 6 days with autologous HIV-infected CD4 ${ }^{+} \mathrm{T}$ cell targets were negatively selected by magnetic automated cell sorting and coincubated with autologous or heterologous $\mathrm{CD} 4^{+} \mathrm{T}$ cell targets (uninfected or infected with the recipient's virus) for 1 hour at $37^{\circ} \mathrm{C}$ to measure killing by granzyme B target cell activity, as described previously $(7,16)$.

To detect IFN- $\gamma$ production or CD107a expression of $\mathrm{CD}^{+} \mathrm{T}$ cells by flow cytometry, pretransfer rested donor and recipient PBMCs were stimulated for 6 hours with the following: medium alone, phorbol myristate acetate (6.5 nM; Calbiochem) plus ionomycin $(0.2 \mu \mathrm{M}$; MilliporeSigma), fresh LIVE/DEAD Fixable Violet Stain-labeled uninfected or HIV-infected CD4 ${ }^{+} \mathrm{T}$ cell targets at a 1:1 effector/target ratio, LIVE/DEAD Fixable Violet Stain-labeled (Invitrogen Molecular Probes) PBMC targets that had been pulsed for 1 hour with the KRWIILGLNK (KK10) consensus sequence peptide or variant KK10 peptide containing the R264Q and L268M mutations (KQWIIMGLNK; Peptide 2.0 Inc.), or pools of 15-amino-acid-long peptides overlapping by 11 amino acids and spanning HIV-1 Env, Nef, Gag, and Pol ( $\geq 80 \%$ purity; each peptide at a final concentration of $2 \mu \mathrm{g} / \mathrm{mL}$; AIDS Reagent Program, Division of AIDS, NIAID, NIH, and Peptide 2.0 Inc.) in 10\% human AB medium containing anti-CD107a-PE Cy7 (BD Pharmingen), monensin (BD GolgiStop; final concentration $0.9 \mu \mathrm{g} / \mathrm{mL}$; BD Biosciences) and brefeldin A (final concentration $10 \mu \mathrm{g} / \mathrm{mL}$; MilliporeSigma), as described previously (16). For HLA B2705-HIV Gag KK10 tetramer-PE (NIH Tetramer Core Facility) staining, stimulated cells were subsequently washed and rested in fresh $10 \%$ human $\mathrm{AB}$ medium at $10^{6}$ cells $/ \mathrm{mL}$ in $15-\mathrm{mL}$ Falcon Polypropylene Sterile Conical Tubes (Corning Inc.) at $37^{\circ} \mathrm{C}$ for 1 hour before tetramer and surface marker staining. Otherwise, stimulated cells were fixed and permeabilized (Cytofix/Cytoperm, BD Biosciences) and stained with the allophycocyanin-conjugated (APC-conjugated) anti-IFN- $\gamma$ antibody (BD Biosciences) before flow cytometry.

After transfer, recipient-derived PBMCs underwent surface staining with anti-CD3-AmCyan (BD Pharmingen), anti-CD8-PerCP (eBioscience), the HLA B2705-HIV Gag KK10 tetramer-PE, anti-CCR7-PECy7 (BD Pharmingen), and anti-CD27-APCCy7 (BioLegend). Cells were subsequently fixed, permeabilized, and stained intracellularly with anti-perforin-BV421 (BD Pharmingen), anti-granzyme B-Alexa Fluor 700 (BD Pharmingen), and anti-Ki67-FITC (eBioscience). Donor and recipient T cells were distinguished during flow cytometry by staining with an APC-labeled anti-human HLA A2 antibody (BioLegend). This antibody was selected among 4 commercially available candidates for brightest fluorescence intensity on PBMCs of HLA-A*2+ donors and lowest nonspecific staining on PBMCs from HLA-A*2- donors. Flow cytometric analysis was performed by 
standard protocols on a BD FACSAria Cell Sorter (BD) as previously described (11). Color compensations were performed using single-stained samples for each of the fluorochromes used. Data were analyzed using FlowJo software (v10.5.3, Tree Star Inc.). Sample flow cytometry gating strategies are shown in Supplemental Figure 1. Posttransfer PBMCs were not available in sufficient numbers to perform a more detailed investigation of $\mathrm{T}$ cell intracellular cytokine production or cytotoxic capacity by flow cytometry.

Specific clones and catalog numbers for the monoclonal antibodies used in the study are listed in Supplemental Table 1.

Chimerism analysis. A chimerism assay based on a published method (53) was used to quantitate the level of donor cells in the recipient's PBMCs. Donor and recipient DNAs were tested with 19 primer pairs to identify a locus that was negative for the recipient but positive for donor DNA. A primer pair from this locus (marker S 06) was used to estimate the level of donor DNA in the recipient DNA by real-time PCR. Primers and probe sequences are as follows: forward primer, 5'-AGGGACTAGCTCATCGGGGTA-3'; reverse primer, 5'-CCTCAGCCCTAATAAAGACAT-3'; and probe, 5'-CCCATCCATCTTCCCTACCAGACCAGG-3'. Three hundred to 600 ng of input DNA, equal to approximately 50,000 to 100,000 cells, was used per assay. A mixture of ratios of donor and recipient DNA was used as a standard. The lower limit of detection was approximately 1 in 50,000 to 100,000 cells, depending on the amount of input DNA.

Cytokine determination. Plasma levels of cytokines and chemokines were measured using the V-PLEX Human Cytokine 30-Plex Kit (Meso Scale Diagnostics), according to the manufacturer's instructions.

Statistics. This study reports the results for a single patient following a single infusion of PBMCs. Results are descriptive, showing single values at different time points, with no calculation of statistical significance given the limited data set.

Study approval. The protocol was approved by the NIAID Institutional Review Board, and both participants provided written informed consent. The protocol was conducted under an Investigational New Drug Application-approved by the US Food and Drug Administration. The trial was registered at ClinicalTrials. gov, with identifier NCT00559416.

\section{Author contributions}

SAM, MP, MC, HCL, and JAK conceived and developed the study concept. CC, MP, SFL, DS, CGM, and JAK conducted the clinical trial. SAM, SL, NVG, DMR, VN, AR, RD, TR, BTS, JA, MC, and JAK performed the in vitro experiments or data analysis. SAM and JAK wrote the draft manuscript, and SAM, CC, SL, NVG, DMR, MP, VN, AR, RD, TR, BTS, JA, SFL, DS, CGM, MC, HCL, and JAK contributed to revisions and read and approved the final manuscript.

\section{Acknowledgments}

The authors would like to thank the patient volunteers for their participation in this study and Hanh Khuu and the Cell Processing Section staff in the Department of Transfusion Medicine for their important contributions. The B2705-HIV Gag KRWIILGLNK (KK10) tetramer was obtained through the NIH Tetramer Core Facility. This project has been funded in whole or in part with federal funds from the Intramural Research Programs of the NIH Clinical Center; the NIAID; the National Cancer Institute; and the NIH under contract HHSN261200800001E. The content of this publication does not necessarily reflect the views or policies of the Department of Health and Human Services, nor does mention of trade names, commercial products, or organizations imply endorsement by the US Government.

Address correspondence to: Joseph A. Kovacs, Building 10, Room 2C145, MSC 1662, Bethesda, Maryland 20892-1662, USA. Phone: 301.496.9907; Email: jkovacs@nih.gov.

NVG's present address is: Medical Scientist Training Program, University of Minnesota Medical School, Minneapolis, Minnesota, USA.

DMR's present address is: Medical Scientist Training Program, Duke University School of Medicine, Durham, North Carolina, USA.

MP's present address is: PHI Medicine, Washington, DC, USA. 
SFL's present address is: Medical Research Scholars Program, Office of Clinical Research Training and Medical Education, NIH, Bethesda, Maryland, USA.

CGM's present address is: Wake Forest School of Medicine, Winston-Salem, North Carolina, USA.

1. Palella FJ Jr, et al. Declining morbidity and mortality among patients with advanced human immunodeficiency virus infection. HIV Outpatient Study Investigators. N Engl J Med. 1998;338(13):853-860.

2. Kitahata MM, et al. Effect of early versus deferred antiretroviral therapy for HIV on survival. N Engl J Med. 2009;360(18):1815-1826.

3. INSIGHT START Study Group, et al. Initiation of antiretroviral therapy in early asymptomatic HIV infection. $N$ Engl J Med. 2015;373(9):795-807.

4. Coffin JM. HIV population dynamics in vivo: implications for genetic variation, pathogenesis, and therapy. Science. 1995;267(5197):483-489.

5. Margolis AM, Heverling H, Pham PA, Stolbach A. A review of the toxicity of HIV medications. J Med Toxicol. 2014;10(1):26-39. 6. Clutter DS, Jordan MR, Bertagnolio S, Shafer RW. HIV-1 drug resistance and resistance testing. Infect Genet Evol. 2016;46:292-307.

7. Migueles SA, et al. Lytic granule loading of $\mathrm{CD} 8^{+} \mathrm{T}$ cells is required for HIV-infected cell elimination associated with immune control. Immunity. 2008;29(6):1009-1021.

8. Perreau M, Levy Y, Pantaleo G. Immune response to HIV. Curr Opin HIV AIDS. 2013;8(4):333-340

9. Migueles SA, Connors M. Success and failure of the cellular immune response against HIV-1. Nat Immunol. 2015;16(6):563-570.

10. Olson $\mathrm{AD}$, et al. An evaluation of HIV elite controller definitions within a large seroconverter cohort collaboration. PLoS One. 2014;9(1):e86719.

11. Migueles SA, et al. CD8(+) T cell cytotoxic capacity associated with human immunodeficiency virus-1 control can be mediated through various epitopes and human leukocyte antigen types. EBioMedicine. 2015;2(1):46-58.

12. Migueles SA, et al. HLA B*5701 is highly associated with restriction of virus replication in a subgroup of HIV-infected long term nonprogressors. Proc Natl Acad Sci U S A. 2000;97(6):2709-2714.

13. Sáez-Cirión A, et al. HIV controllers exhibit potent CD8 T cell capacity to suppress HIV infection ex vivo and peculiar cytotoxic T lymphocyte activation phenotype. Proc Natl Acad Sci U S A. 2007;104(16):6776-6781.

14. Betts MR, et al. HIV nonprogressors preferentially maintain highly functional HIV-specific CD8 ${ }^{+} \mathrm{T}$ cells. Blood. 2006;107(12):4781-4789.

15. Migueles SA, et al. HIV-specific $\mathrm{CD} 8^{+} \mathrm{T}$ cell proliferation is coupled to perforin expression and is maintained in nonprogressors Nat Immunol. 2002;3(11):1061-1068.

16. Migueles SA, et al. Defective human immunodeficiency virus-specific $\mathrm{CD} 8^{+} \mathrm{T}$ cell polyfunctionality, proliferation, and cytotoxicity are not restored by antiretroviral therapy. J Virol. 2009;83(22):11876-11889.

17. Leen AM, et al. Monoculture-derived $\mathrm{T}$ lymphocytes specific for multiple viruses expand and produce clinically relevant effects in immunocompromised individuals. Nat Med. 2006;12(10):1160-1166.

18. Dave $\mathrm{H}$, et al. Toward a rapid production of multivirus-specific T cells targeting BKV, adenovirus, CMV, and EBV from umbilical cord blood. Mol Ther Methods Clin Dev. 2017;5:13-21.

19. Lane HC, et al. Syngeneic bone marrow transplantation and adoptive transfer of peripheral blood lymphocytes combined with zidovudine in human immunodeficiency virus (HIV) infection. Ann Intern Med. 1990;113(7):512-519.

20. Walker R, et al. A study of the safety and survival of the adoptive transfer of genetically marked syngeneic lymphocytes in HIV-infected identical twins. Hum Gene Ther. 1993;4(5):659-680.

21. Morgan RA, et al. Preferential survival of $\mathrm{CD} 4^{+} \mathrm{T}$ lymphocytes engineered with anti-human immunodeficiency virus (HIV) genes in HIV-infected individuals. Hum Gene Ther. 2005;16(9):1065-1074.

22. Brodie SJ, et al. In vivo migration and function of transferred HIV-1-specific cytotoxic T cells. Nat Med. 1999;5(1):34-41.

23. Walker RE, et al. Long-term in vivo survival of receptor-modified syngeneic $\mathrm{T}$ cells in patients with human immunodeficiency virus infection. Blood. 2000;96(2):467-474.

24. Mitsuyasu RT, et al. Prolonged survival and tissue trafficking following adoptive transfer of CD4zeta gene-modified autologous CD4(+) and CD8(+) T cells in human immunodeficiency virus-infected subjects. Blood. 2000;96(3):785-793.

25. Bolton DL, et al. Trafficking, persistence, and activation state of adoptively transferred allogeneic and autologous Simian Immunodeficiency Virus-specific CD8(+) T cell clones during acute and chronic infection of rhesus macaques. J Immunol. 2010;184(1):303-314.

26. Ferre AL, et al. Mucosal immune responses to HIV-1 in elite controllers: a potential correlate of immune control. Blood. 2009;113(17):3978-3989.

27. Hamann D, et al. Phenotypic and functional separation of memory and effector human CD8 ${ }^{+} \mathrm{T}$ cells. $J$ Exp Med. 1997;186(9):1407-1418.

28. Sallusto F, Lenig D, Förster R, Lipp M, Lanzavecchia A. Two subsets of memory T lymphocytes with distinct homing potentials and effector functions. Nature. 1999;401(6754):708-712.

29. Hillhouse EE, Lesage S. A comprehensive review of the phenotype and function of antigen-specific immunoregulatory double negative T cells. $J$ Autoimmun. 2013;40:58-65.

30. Lee TH, Paglieroni T, Ohto H, Holland PV, Busch MP. Survival of donor leukocyte subpopulations in immunocompetent transfusion recipients: frequent long-term microchimerism in severe trauma patients. Blood. 1999;93(9):3127-3139.

31. Schmitz JE, et al. Control of viremia in simian immunodeficiency virus infection by CD8 $8^{+}$lymphocytes. Science. 1999;283(5403):857-860.

32. Jin $\mathrm{X}$, et al. Dramatic rise in plasma viremia after $\mathrm{CD} 8(+) \mathrm{T}$ cell depletion in simian immunodeficiency virus-infected macaques. J Exp Med. 1999;189(6):991-998.

33. Chowdhury A, et al. Differential impact of in vivo $\mathrm{CD} 8^{+} \mathrm{T}$ lymphocyte depletion in controller versus progressor Simian Immu- 
nodeficiency Virus-infected macaques. J Virol. 2015;89(17):8677-8686.

34. Malhotra U, et al. Role for HLA class II molecules in HIV-1 suppression and cellular immunity following antiretroviral treatment. J Clin Invest. 2001;107(4):505-517.

35. Zaunders JJ, et al. Identification of circulating antigen-specific $\mathrm{CD}^{+} \mathrm{T}$ lymphocytes with a CCR5 $5^{+}$, cytotoxic phenotype in an HIV-1 long-term nonprogressor and in CMV infection. Blood. 2004;103(6):2238-2247.

36. Norris PJ, et al. Beyond help: direct effector functions of human immunodeficiency virus type 1-specific CD4(+) T cells. $J$ Virol. 2004;78(16):8844-8851.

37. Ferre AL, et al. HIV controllers with HLA-DRB1*13 and HLA-DQB1*06 alleles have strong, polyfunctional mucosal CD4 ${ }^{+} \mathrm{T}$ cell responses. J Virol. 2010;84(21):11020-11029.

38. Almeida CA, et al. Stimulation of HIV-specific T cell clonotypes using allogeneic HLA. Cell Immunol. 2017;316:32-40.

39. Peris-Pertusa A, López M, Rallón NI, Restrepo C, Soriano V, Benito JM. Evolution of the functional profile of HIV-specific $\mathrm{CD}^{+} \mathrm{T}$ cells in patients with different progression of HIV infection over 4 years. J Acquir Immune Defic Syndr. 2010;55(1):29-38.

40. Younes SA, et al. IL-15 promotes activation and expansion of CD8+ T cells in HIV-1 infection. J Clin Invest. 2016;126(7):2745-2756.

41. Mueller YM, et al. IL-15 treatment during acute simian immunodeficiency virus (SIV) infection increases viral set point and accelerates disease progression despite the induction of stronger SIV-specific CD8+ T cell responses. J Immunol. 2008;180(1):350-360.

42. Picker LJ, et al. IL-15 induces CD4 effector memory T cell production and tissue emigration in nonhuman primates. $J$ Clin Invest. 2006;116(6):1514-1524.

43. Villinger F, et al. IL-15 is superior to IL-2 in the generation of long-lived antigen specific memory CD4 and CD8 T cells in rhesus macaques. Vaccine. 2004;22(25-26):3510-3521.

44. Koenig S, et al. Transfer of HIV-1-specific cytotoxic T lymphocytes to an AIDS patient leads to selection for mutant HIV variants and subsequent disease progression. Nat Med. 1995;1(4):330-336.

45. Chun TW, et al. Effect of interleukin- 2 on the pool of latently infected, resting CD4 ${ }^{+} \mathrm{T}$ cells in HIV-1-infected patients receiving highly active anti-retroviral therapy. Nat Med. 1999;5(6):651-655.

46. Prins JM, et al. Immuno-activation with anti-CD3 and recombinant human IL-2 in HIV-1-infected patients on potent antiretroviral therapy. AIDS. 1999;13(17):2405-2410.

47. Kulkosky J, et al. Intensification and stimulation therapy for human immunodeficiency virus type 1 reservoirs in infected persons receiving virally suppressive highly active antiretroviral therapy. J Infect Dis. 2002;186(10):1403-1411.

48. Gay CL, et al. Clinical trial of the anti-PD-L1 antibody BMS-936559 in HIV-1 infected participants on suppressive antiretroviral therapy. J Infect Dis. 2017;215(11):1725-1733

49. Velu V, et al. Enhancing SIV-specific immunity in vivo by PD-1 blockade. Nature. 2009;458(7235):206-210.

50. Collier AC, et al. Leukocyte-reduced red blood cell transfusions in patients with anemia and human immunodeficiency virus infection: the Viral Activation Transfusion Study: a randomized controlled trial. JAMA. 2001;285(12):1592-1601.

51. Rühl H, Bein G, Sachs UJ. Transfusion-associated graft-versus-host disease. Transfus Med Rev. 2009;23(1):62-71.

52. Sievers F, et al. Fast, scalable generation of high-quality protein multiple sequence alignments using Clustal Omega. Mol Syst Biol. 2011;7:539.

53. Alizadeh M, et al. Quantitative assessment of hematopoietic chimerism after bone marrow transplantation by real-time quantitative polymerase chain reaction. Blood. 2002;99(12):4618-4625. 